TITLE:

\title{
Geo-Disaster and Its Mitigation in Nepal
}

\author{
$\operatorname{AUTHOR}(S)$ :
}

Dahal, Ranjan-Kumar; Bhandary, Netra-Prakash

\section{CITATION:}

Dahal, Ranjan-Kumar ... [et al]. Geo-Disaster and Its Mitigation in Nepal. Matsue Conference Proceedings (The Tenth International Symposium on Mitigation of Geo-disasters in Asia 2012: 27-32: 共同研究（一般研究集会）24K-02.

ISSUE DATE:

2012-10-08

URL:

http://hdl.handle.net/2433/180421

RIGHT: 

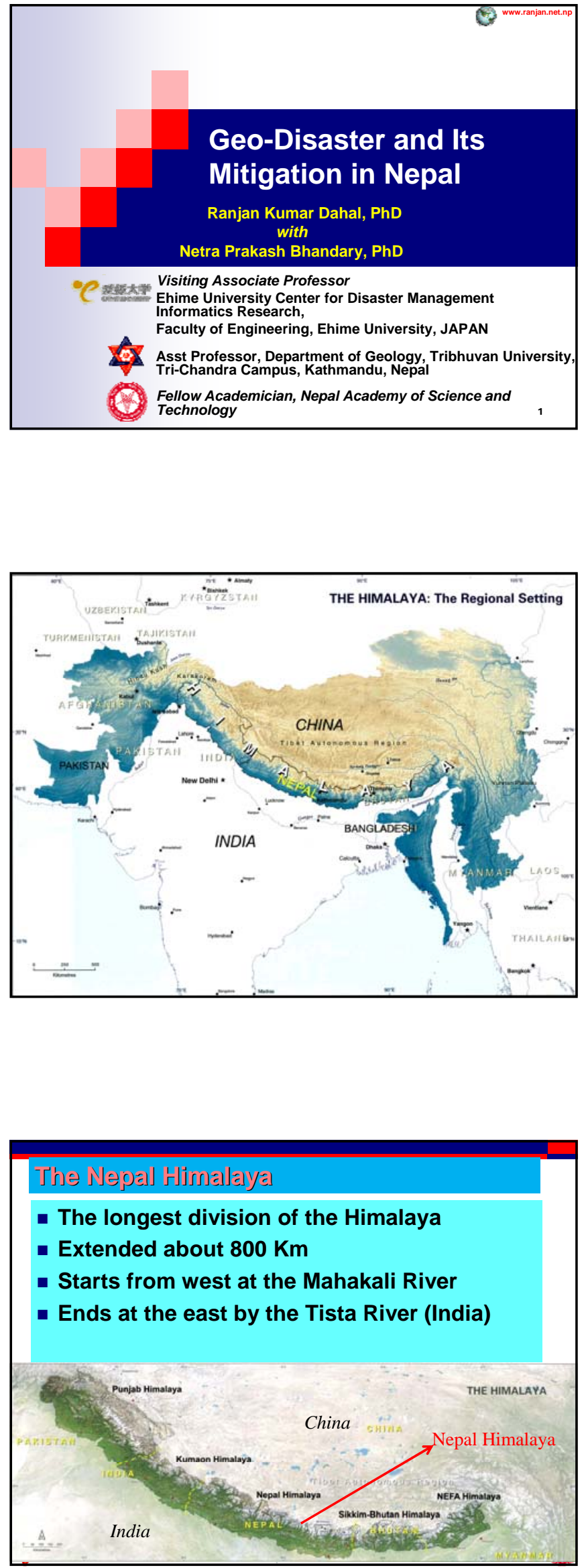
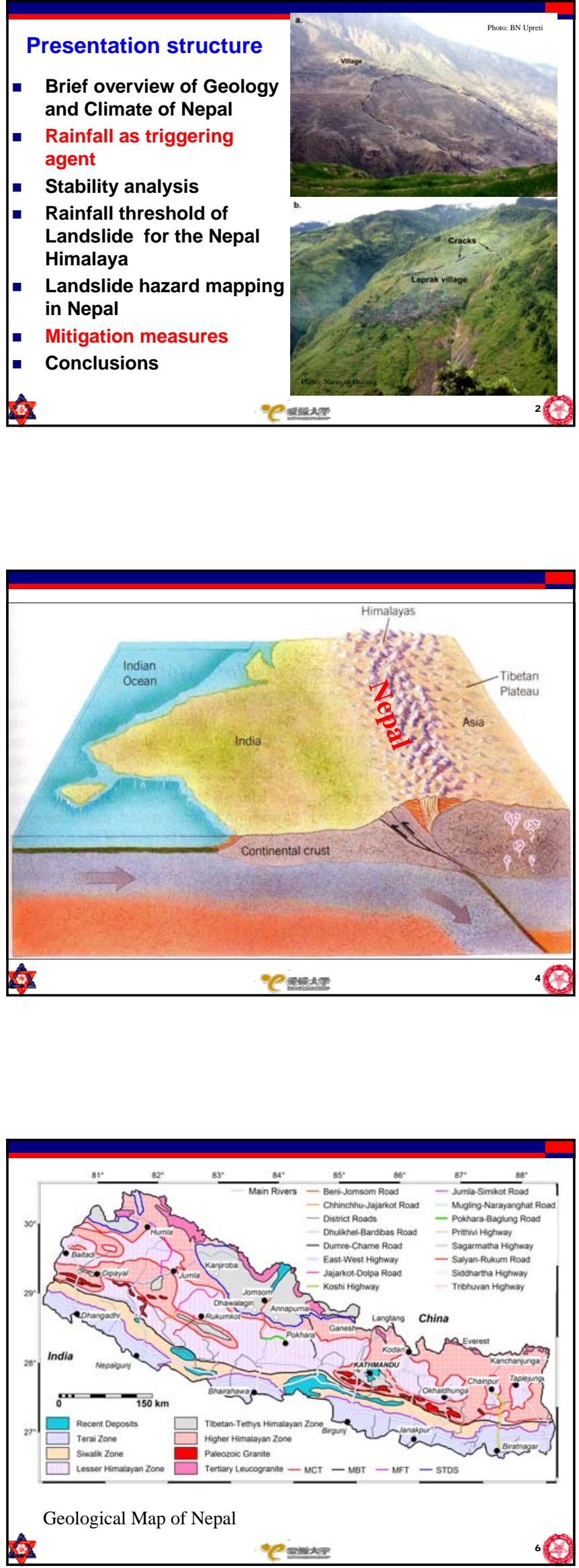

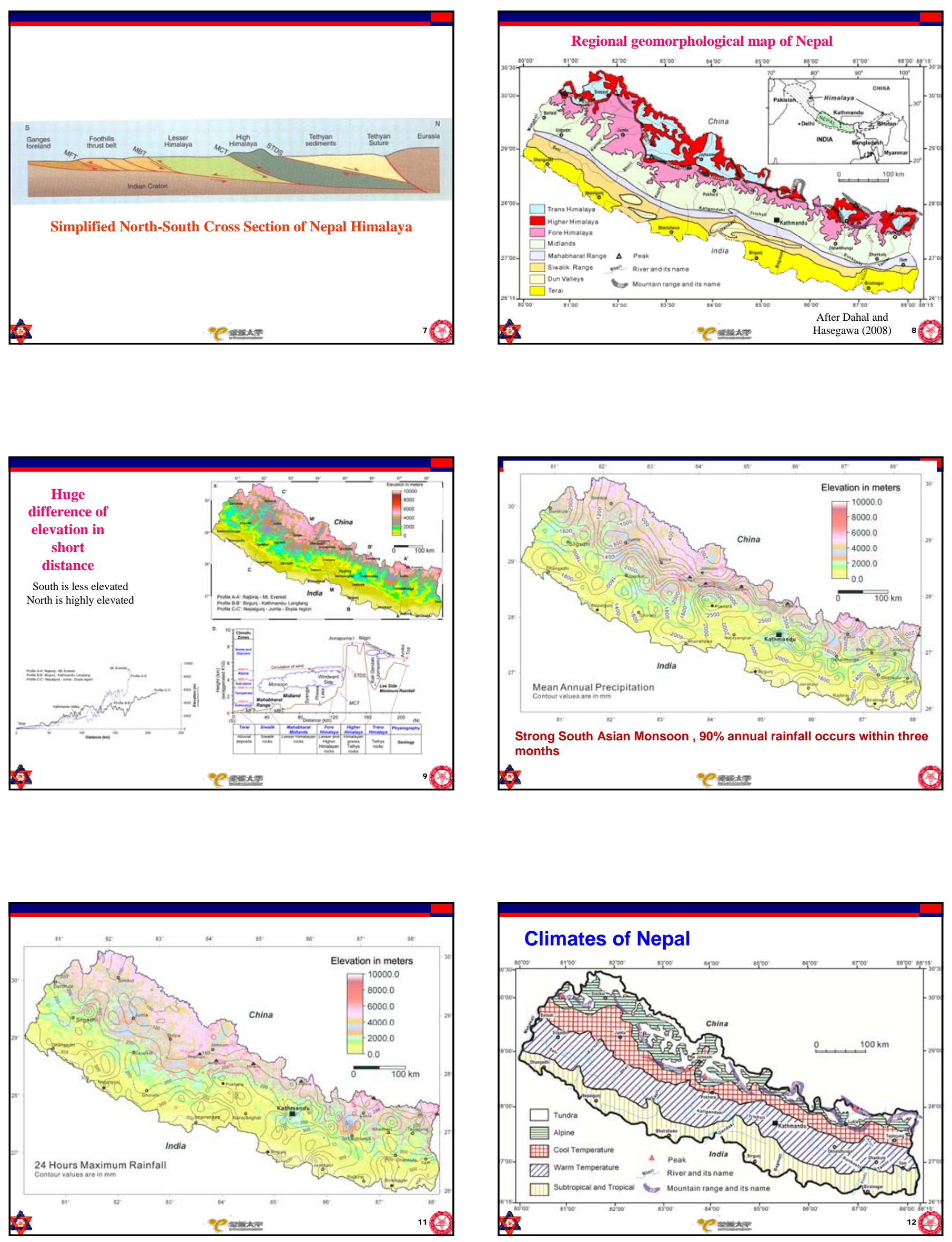

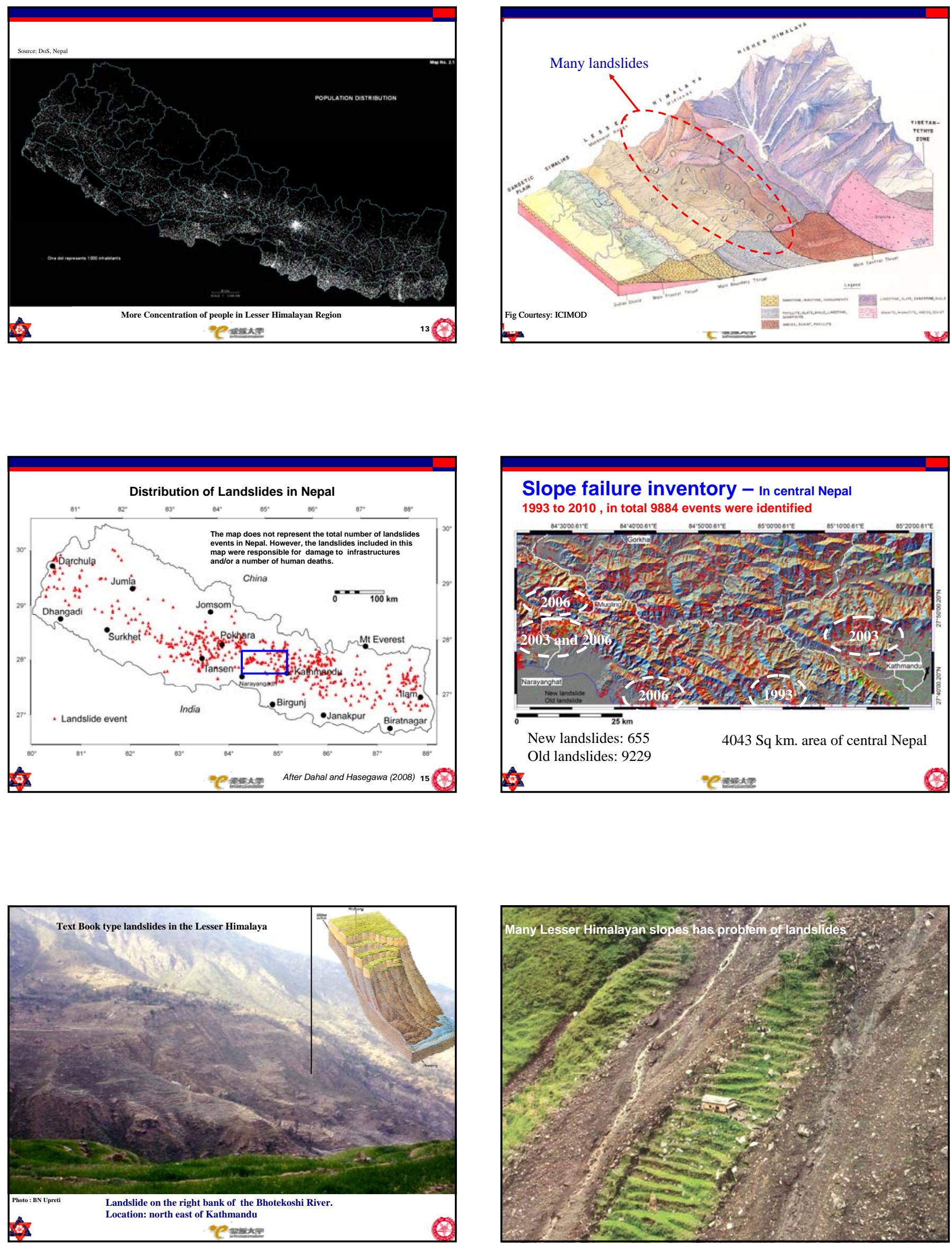

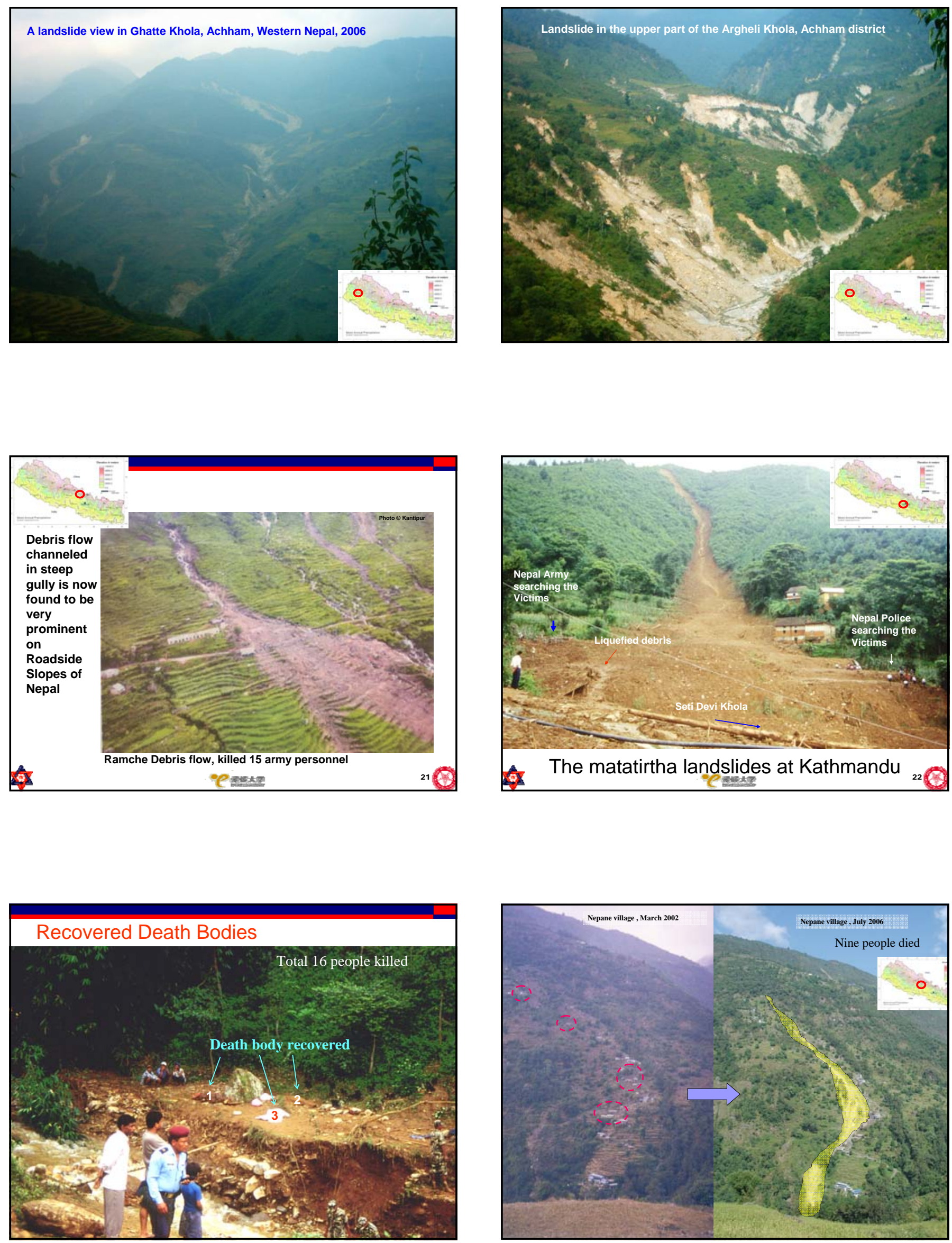

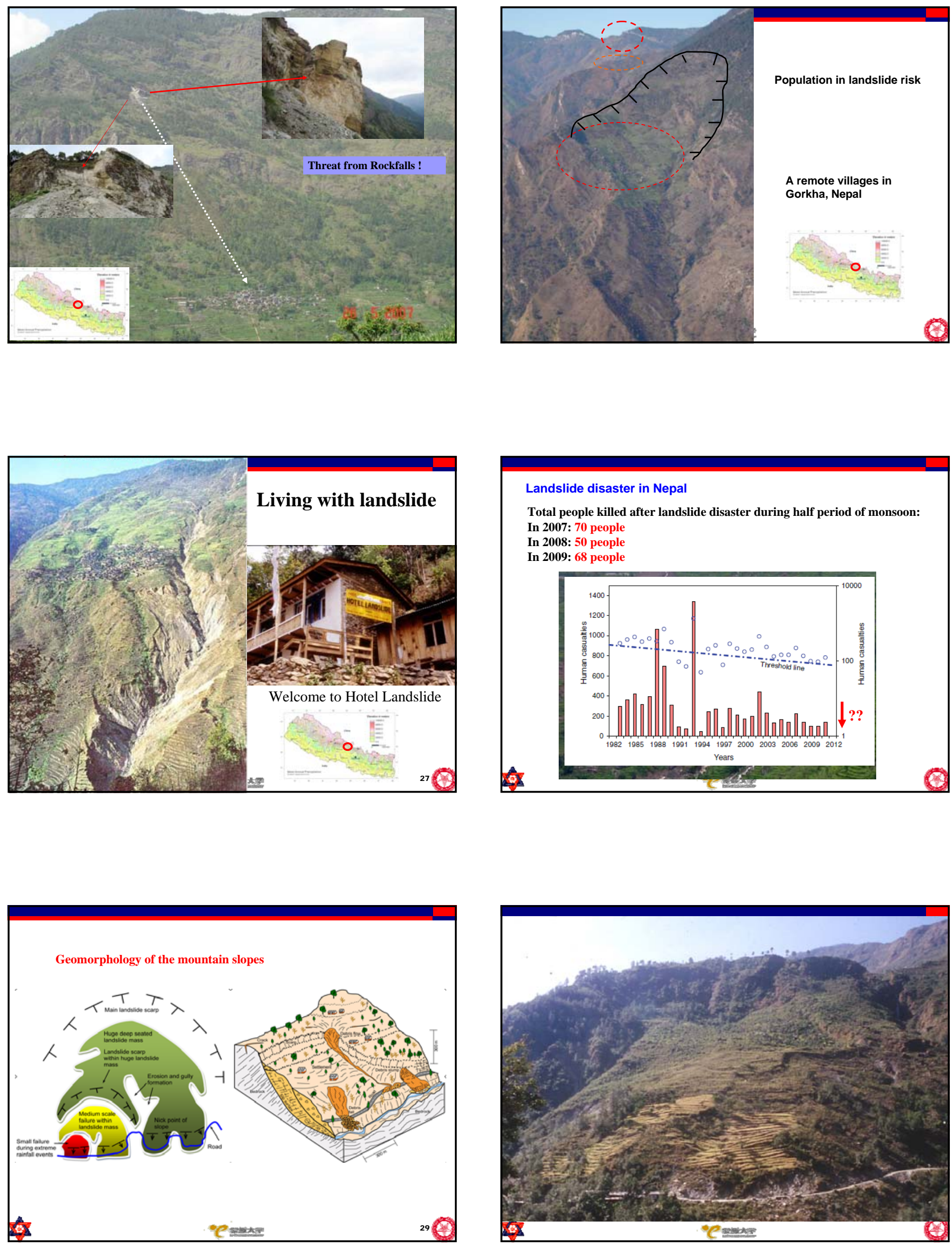

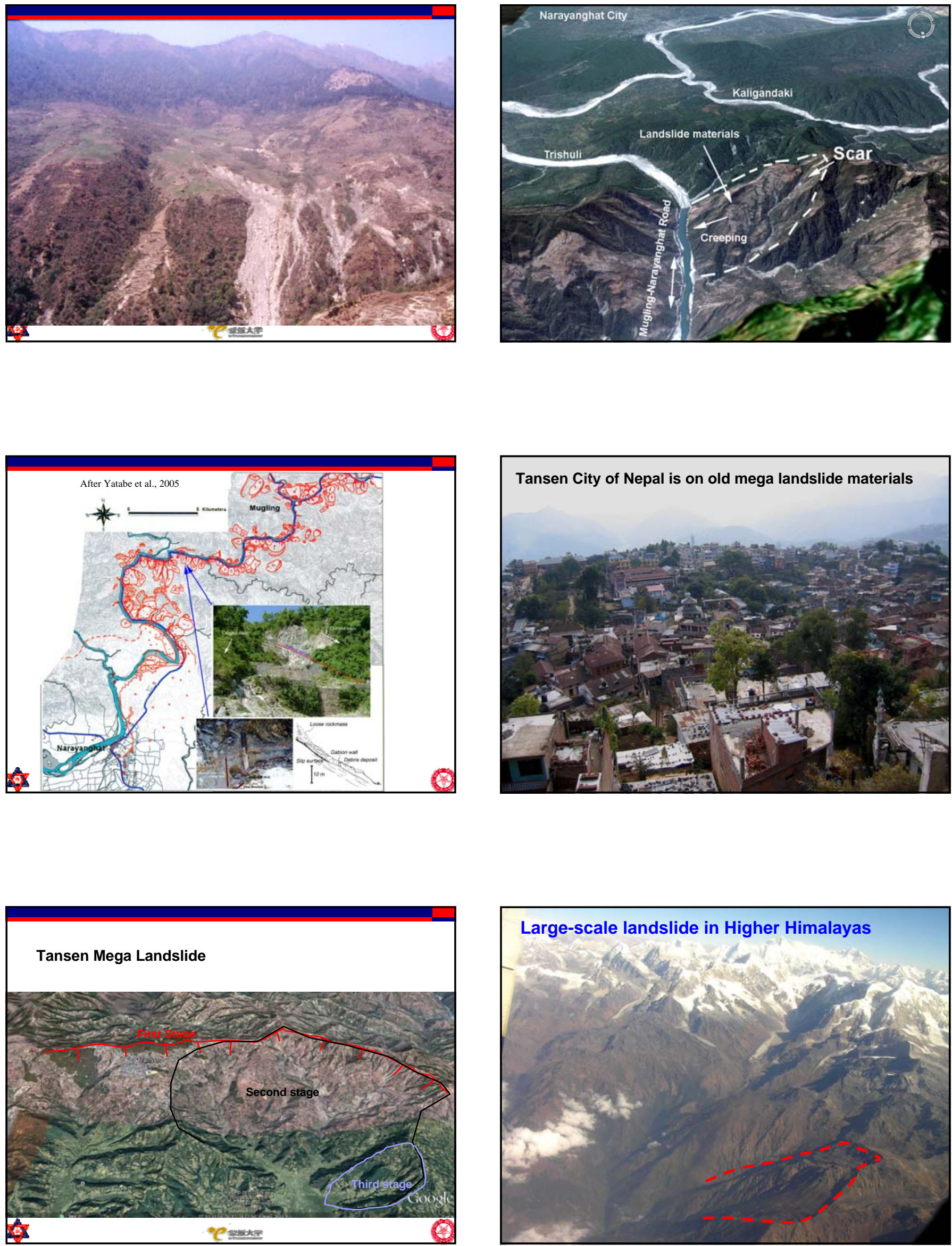

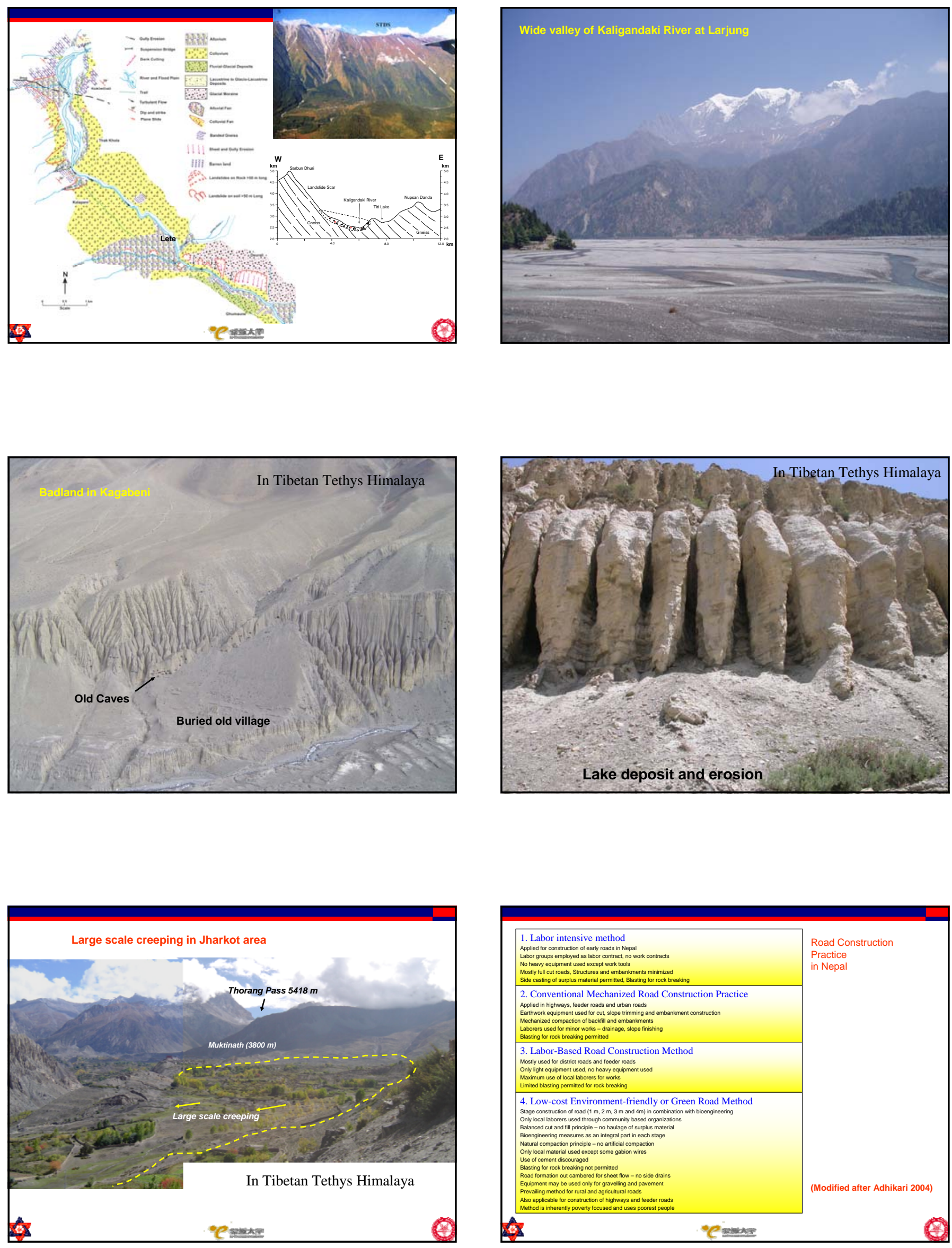

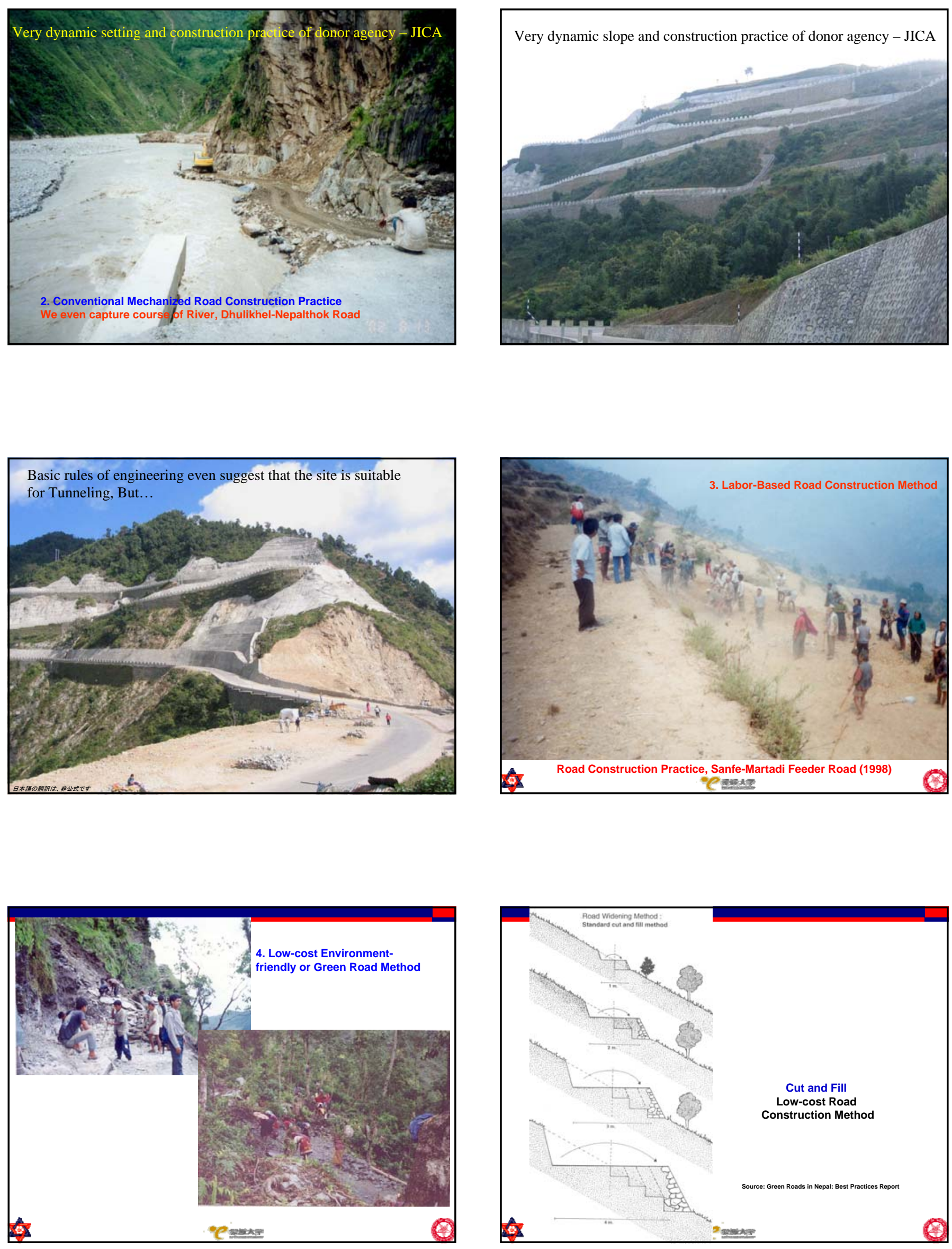

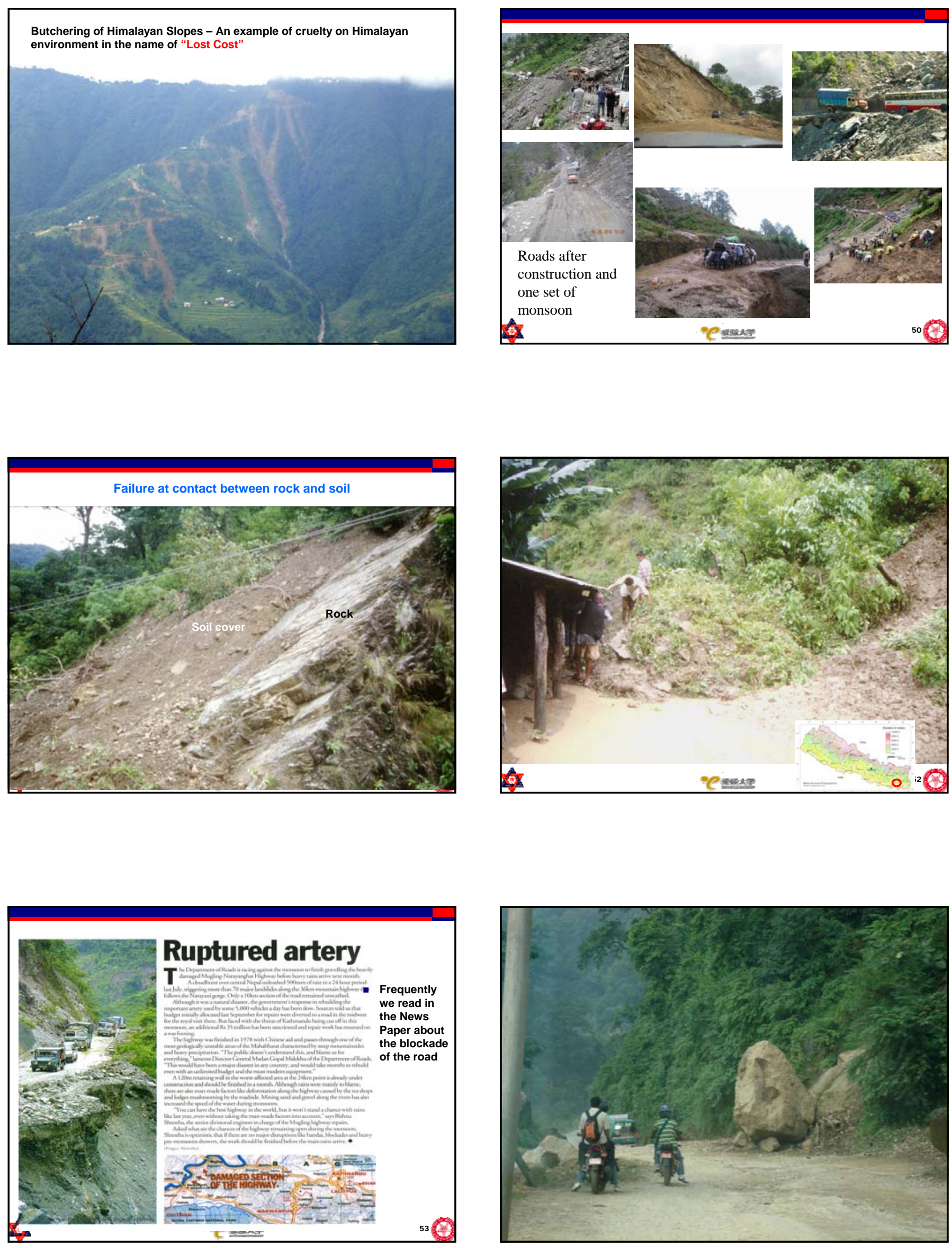

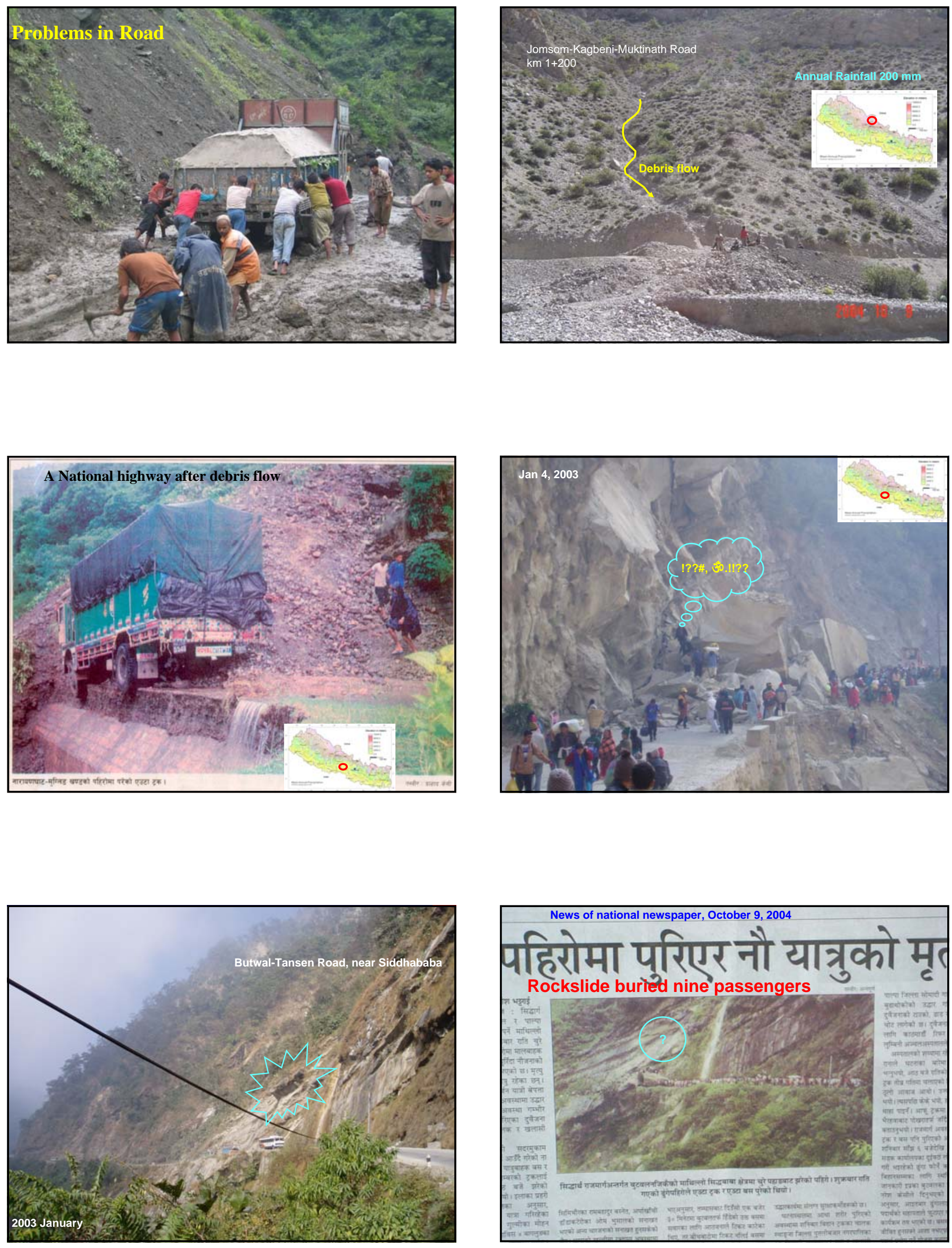

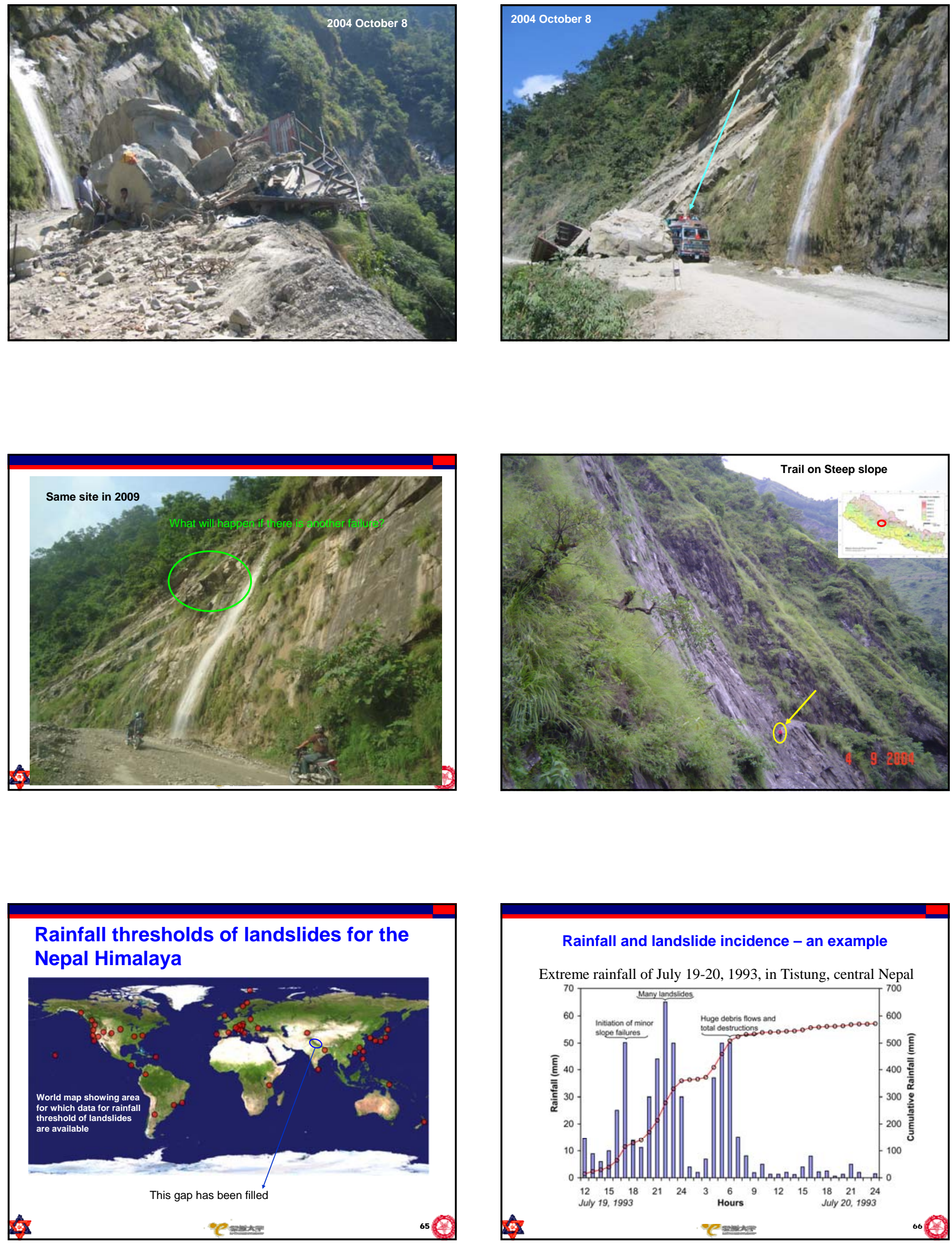

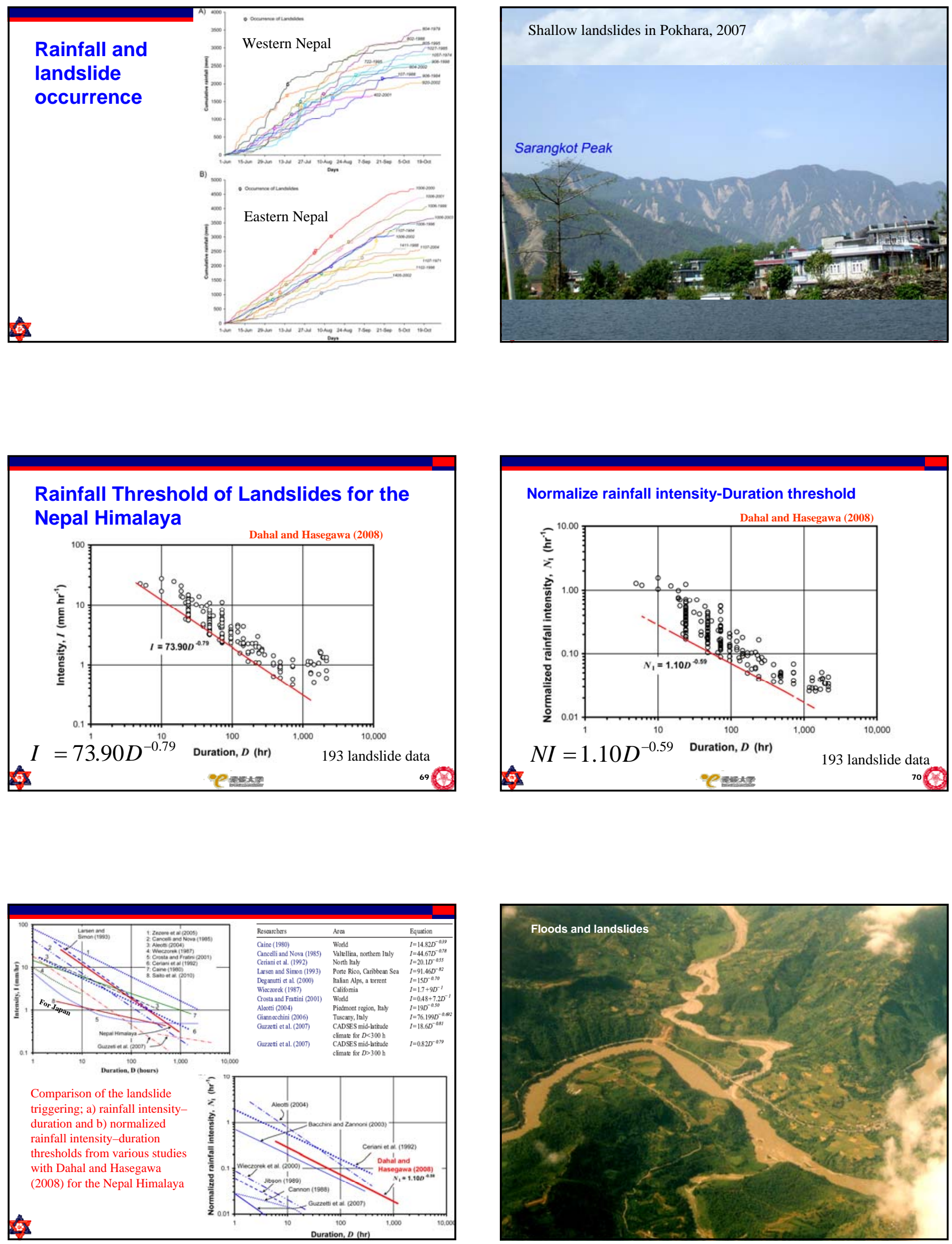

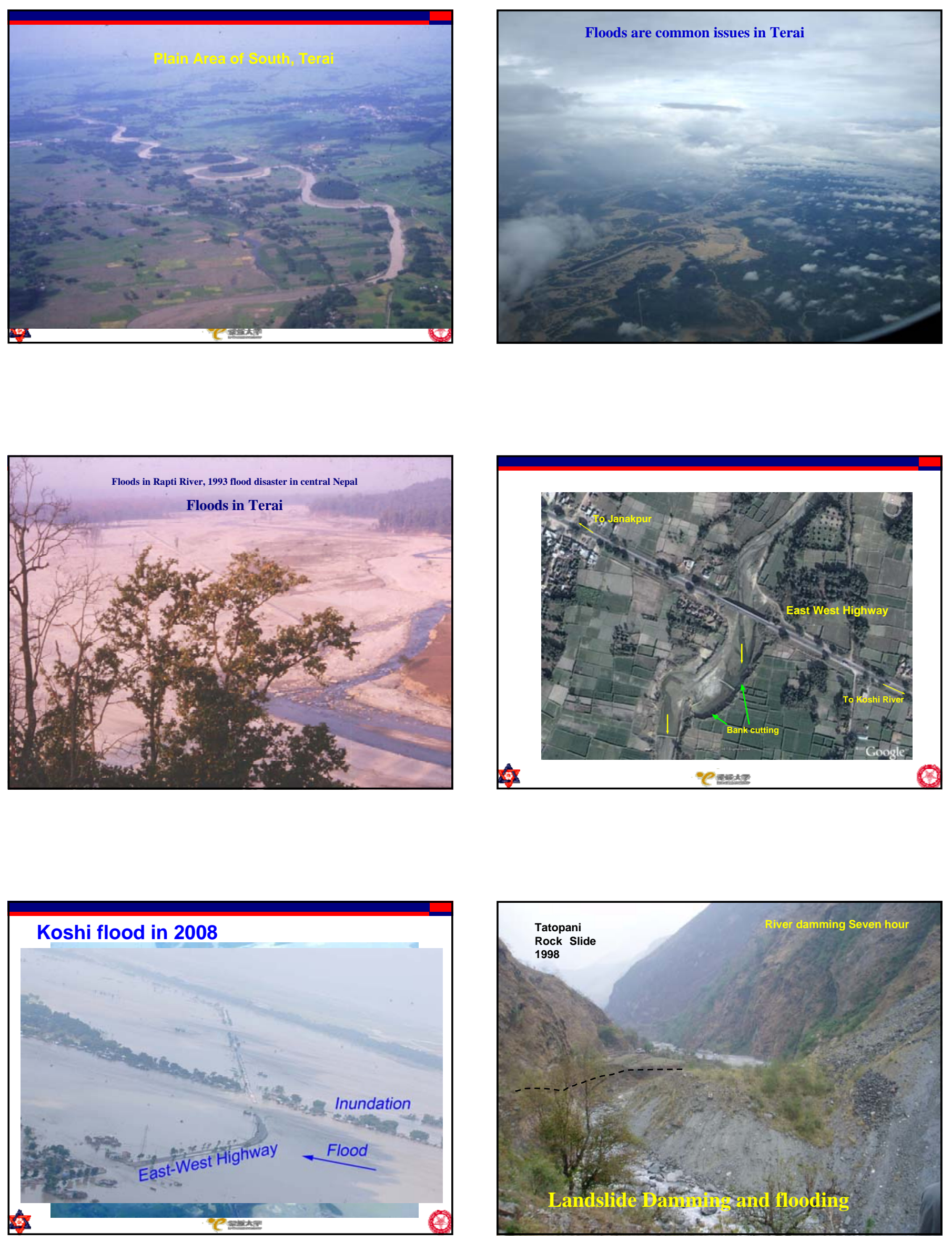

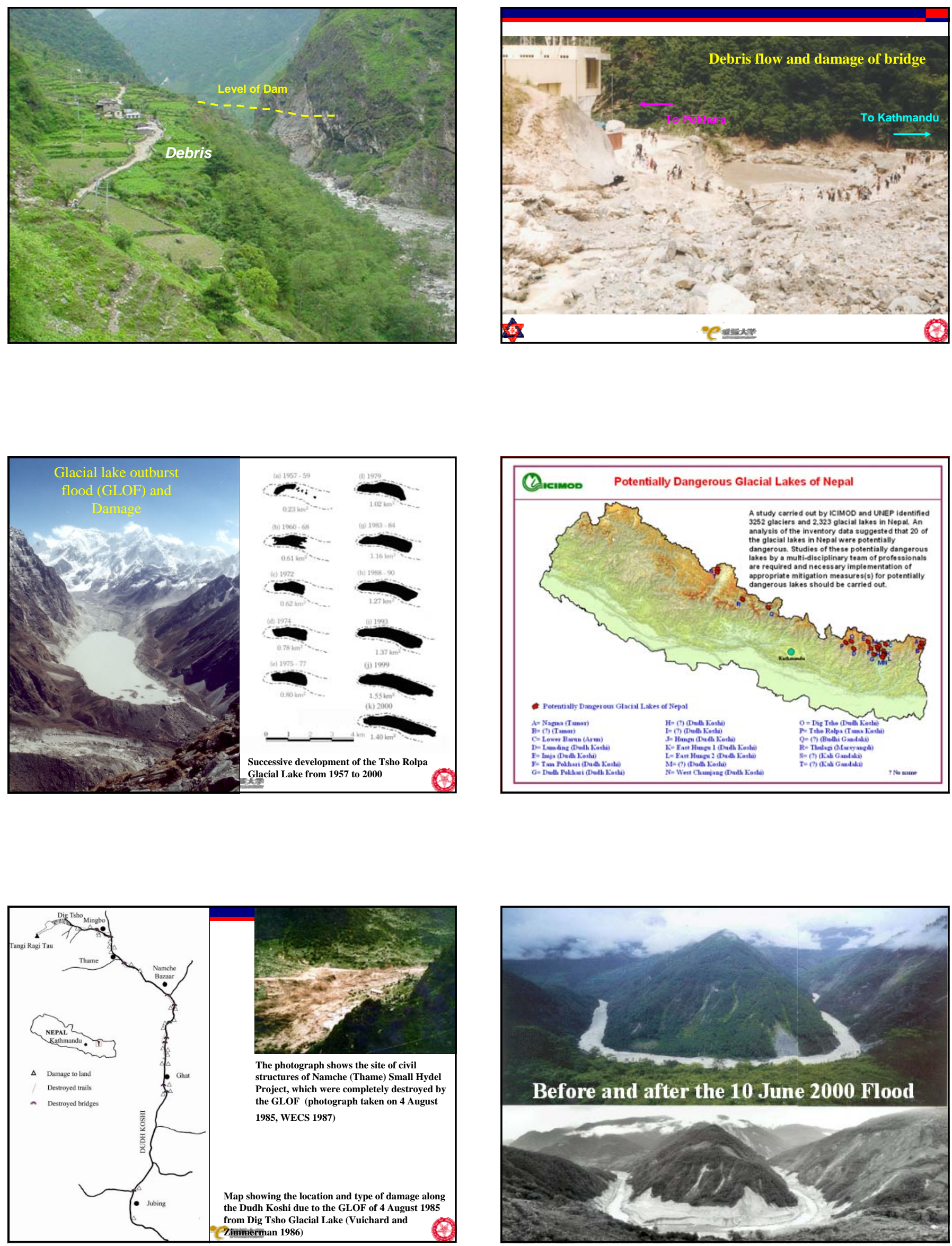

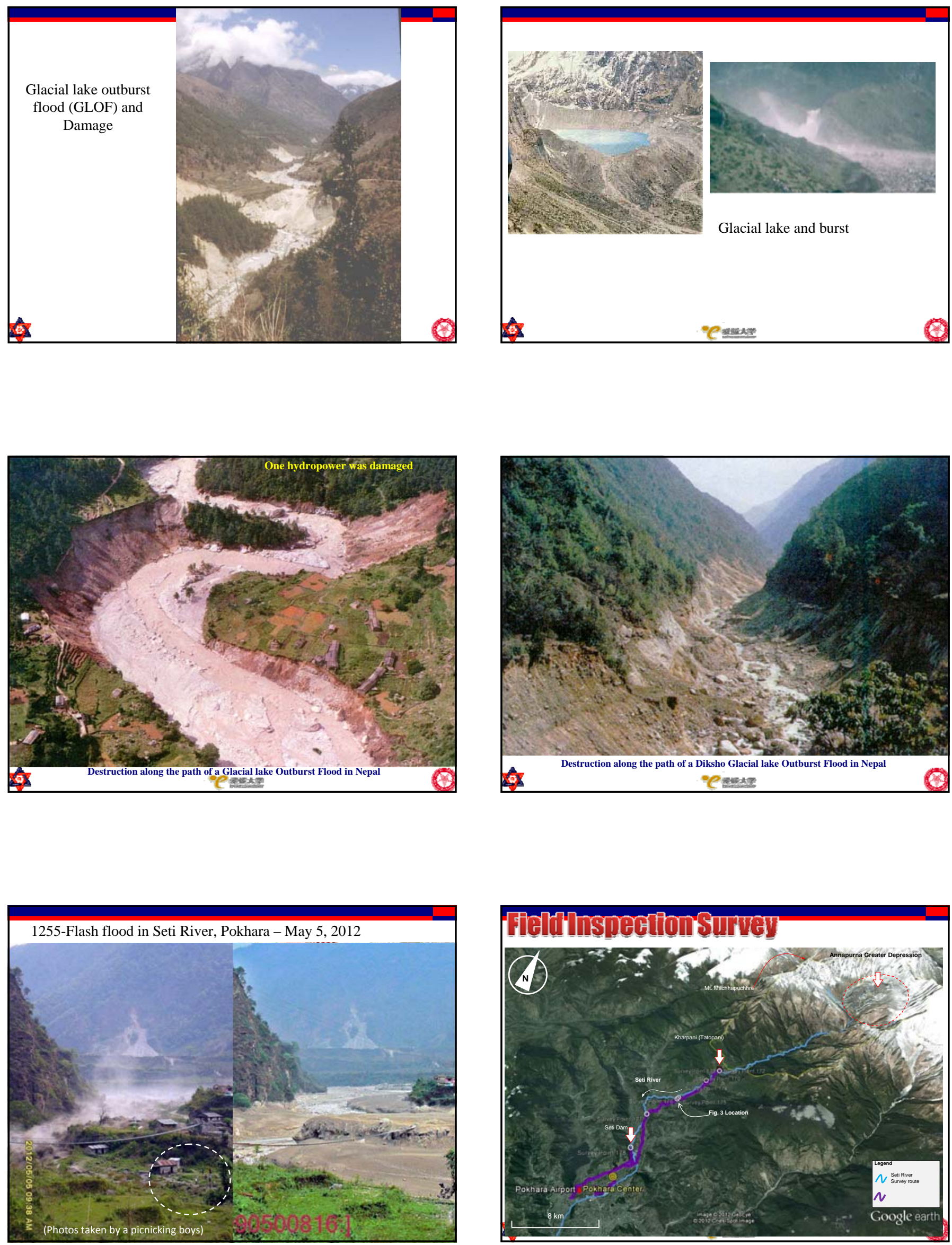

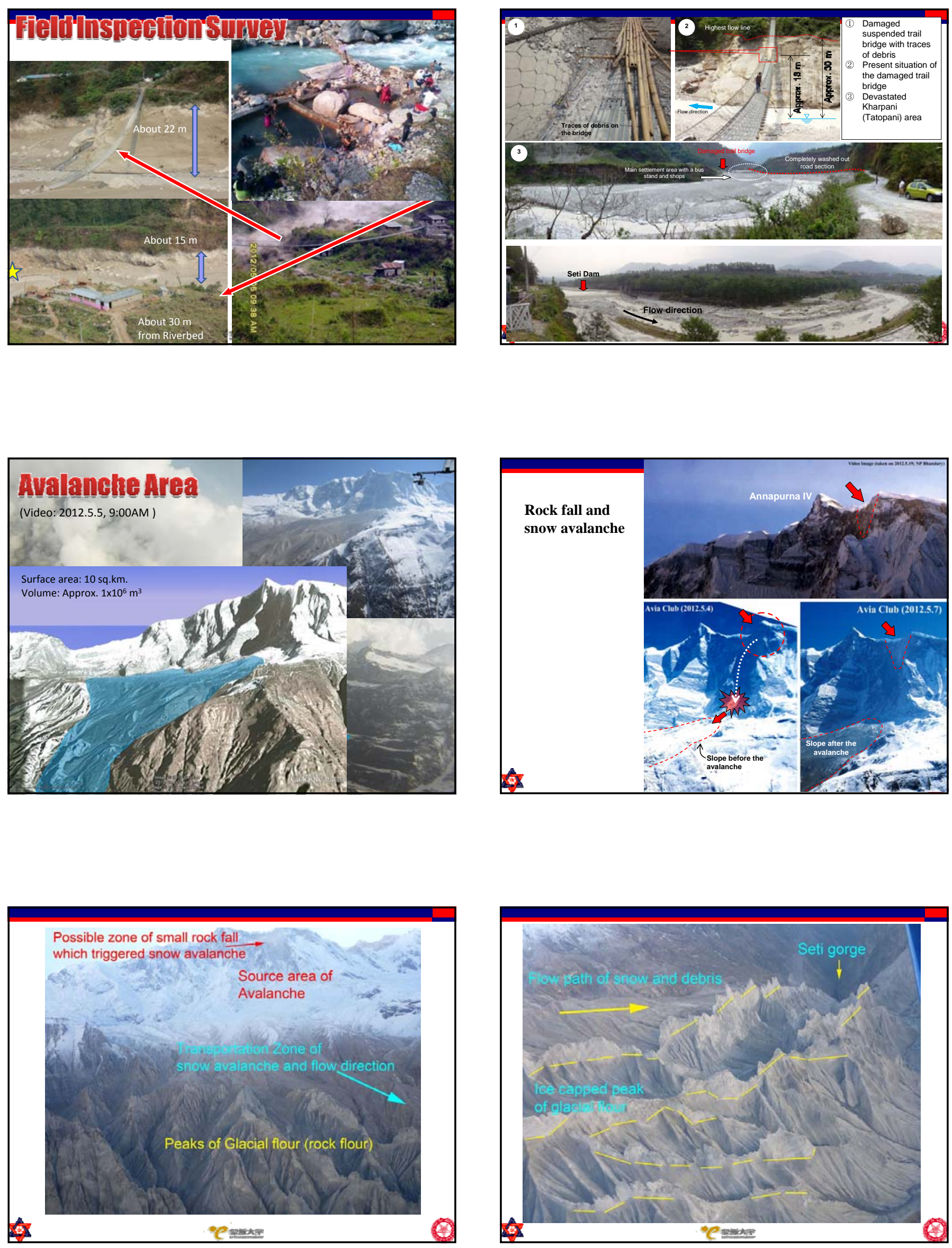

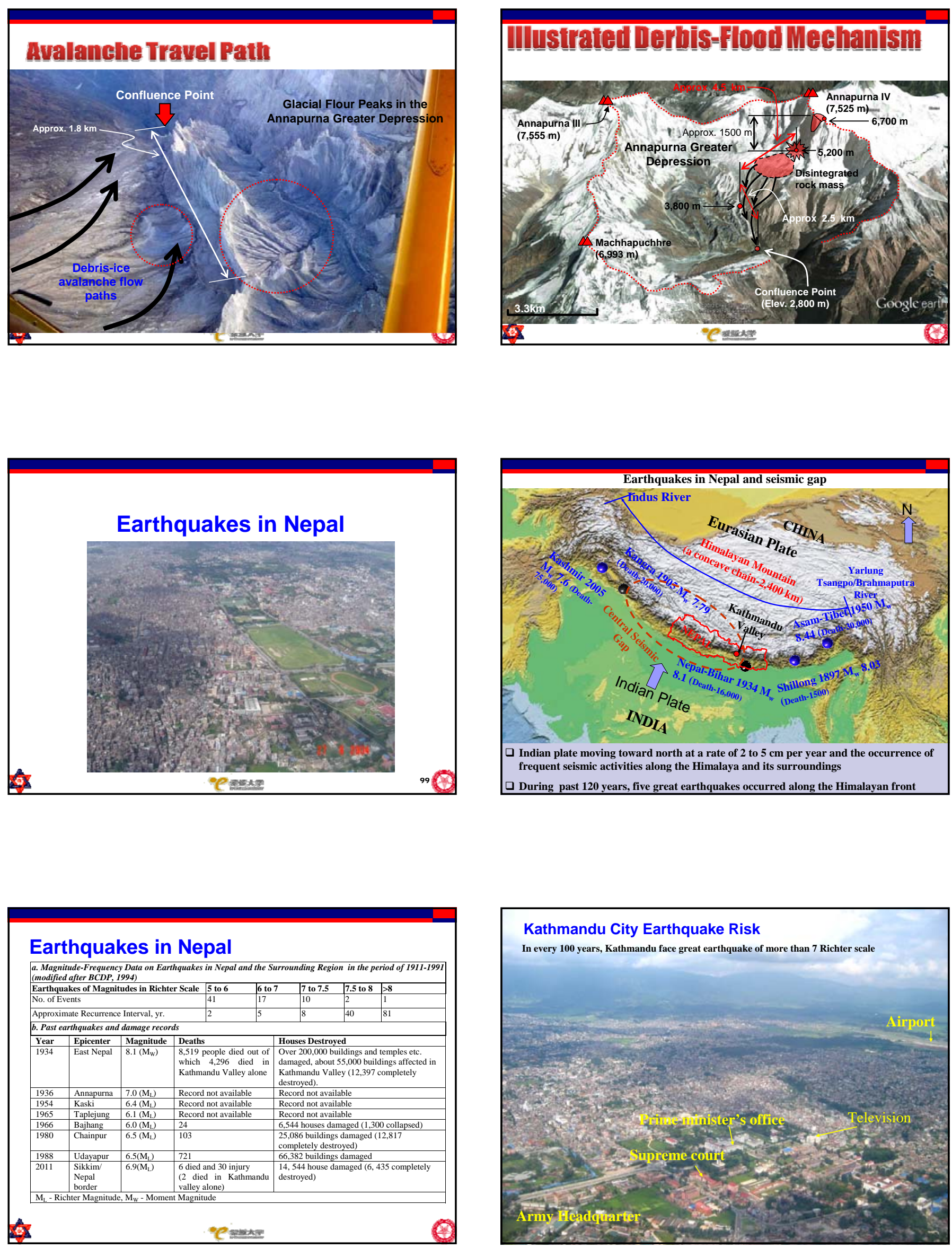

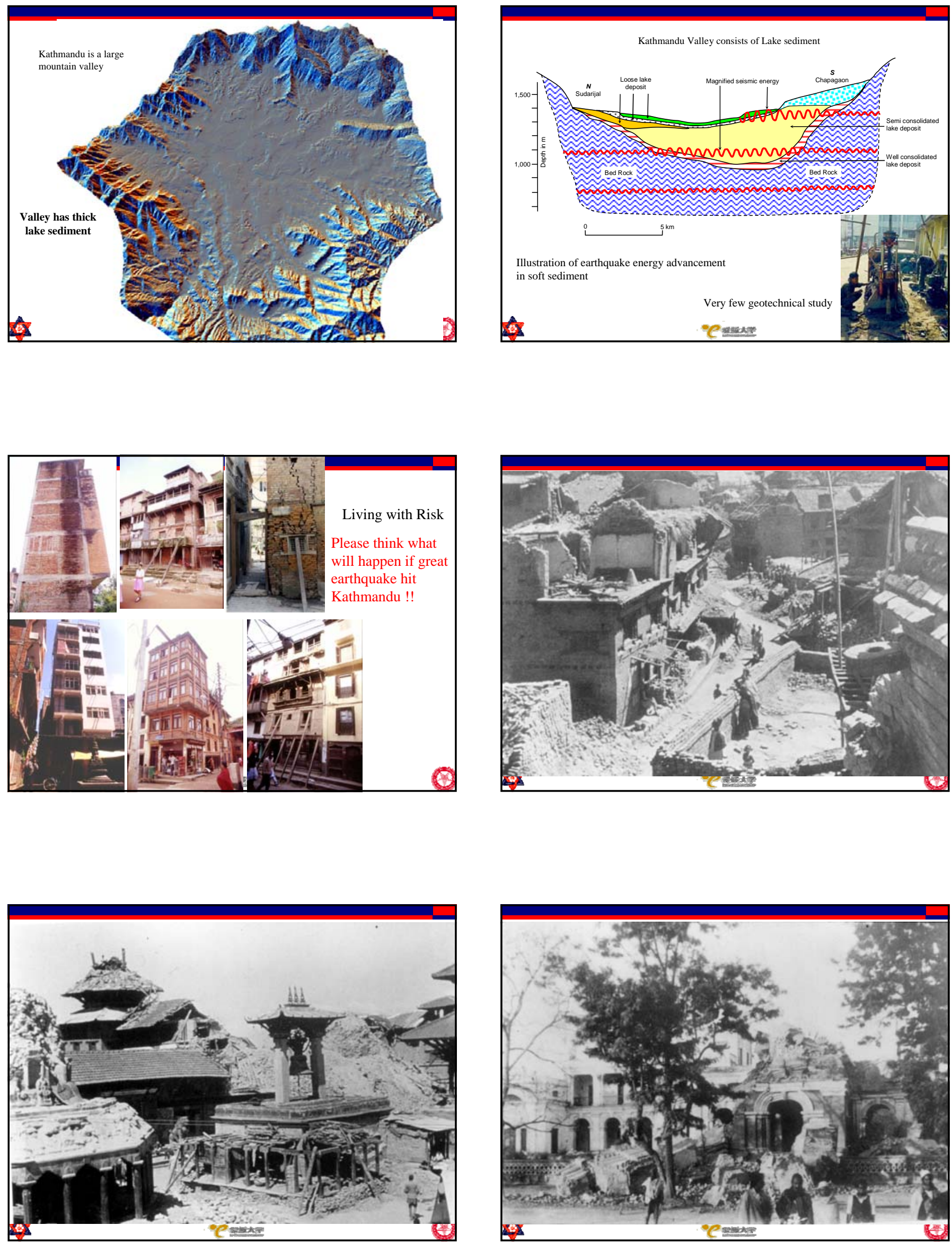

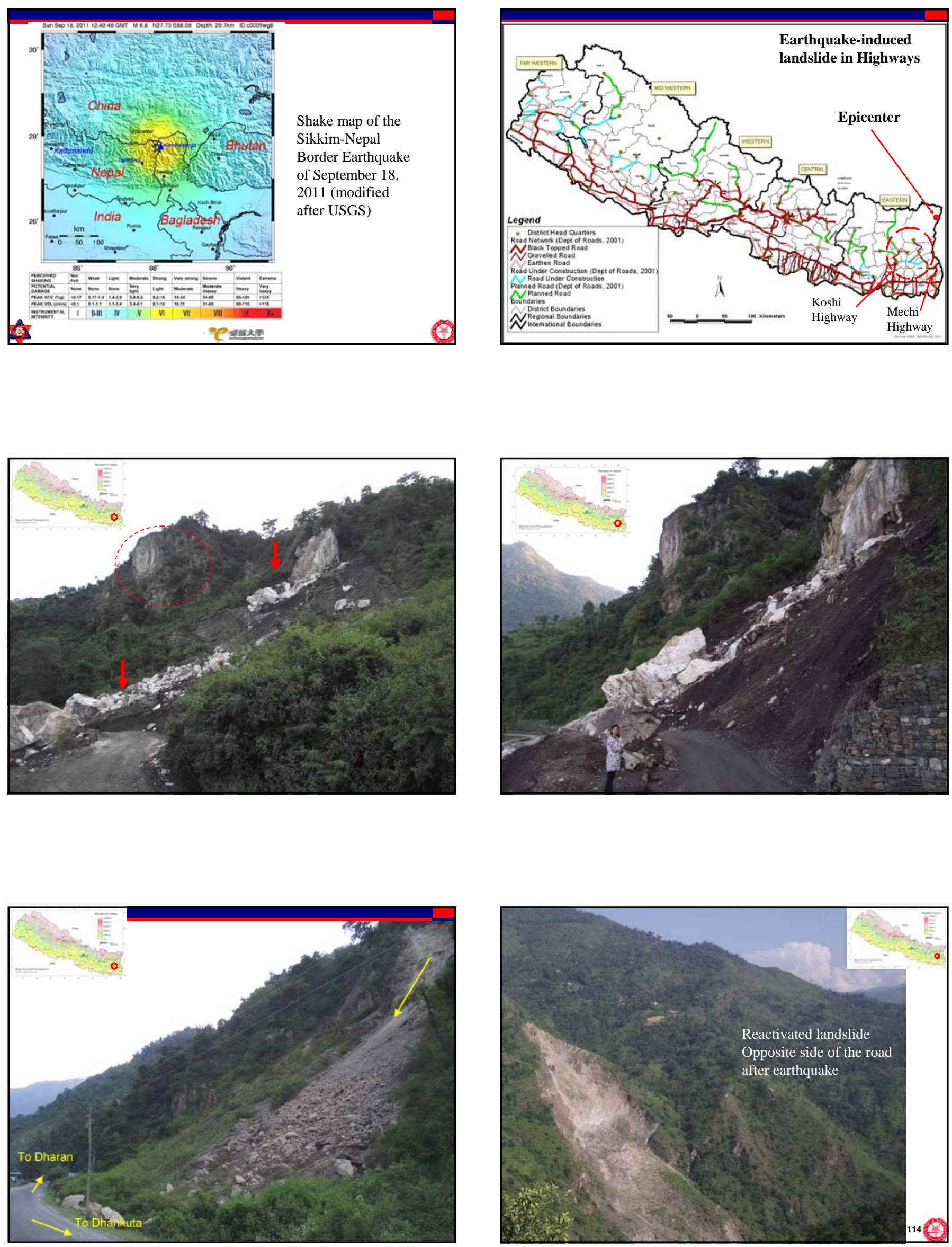

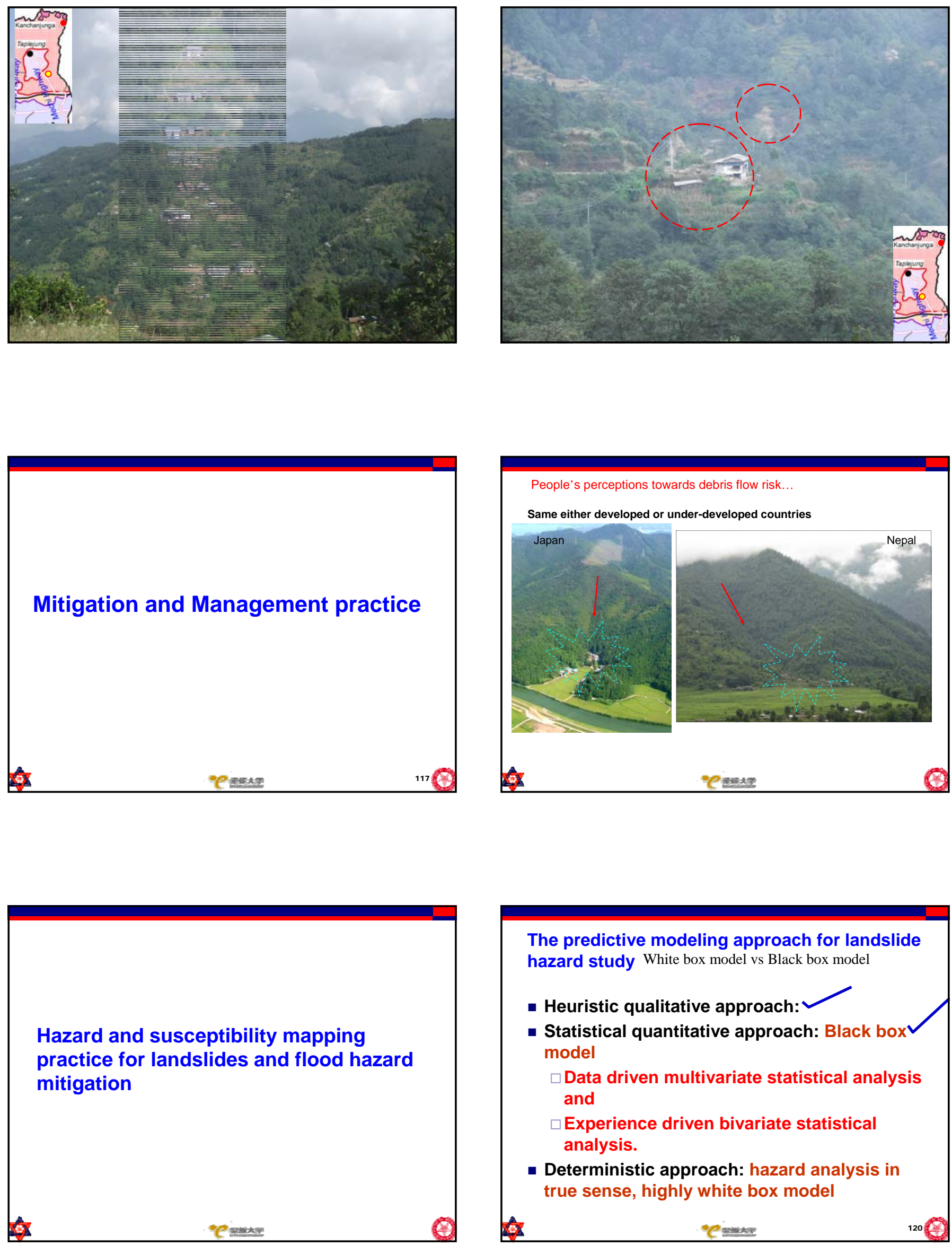

The predictive modeling approach for landslide hazard study White box model vs Black box model

- Heuristic qualitative approach:

- Statistical quantitative approach: Black box model

$\square$ Data driven multivariate statistical analysis and

$\square$ Experience driven bivariate statistical analysis.

- Deterministic approach: hazard analysis in true sense, highly white box model 
Management of landslide hazard zones

Community participation

- Till date no definite initiation from government, only few works

- The hazard maps should be brought into the knowledge of local people in order to aware and motivate them in proper land use and disaster management practices.

鱼

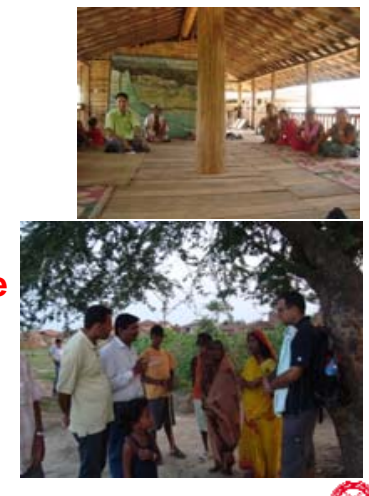

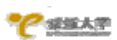
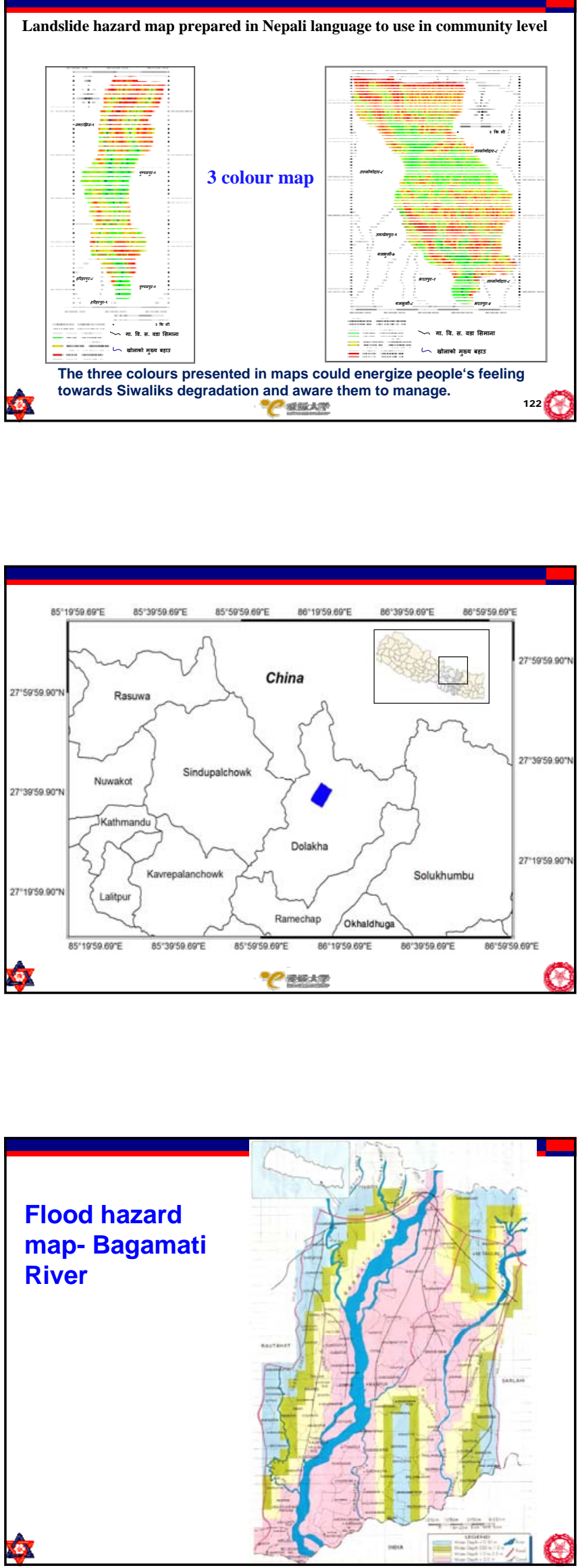

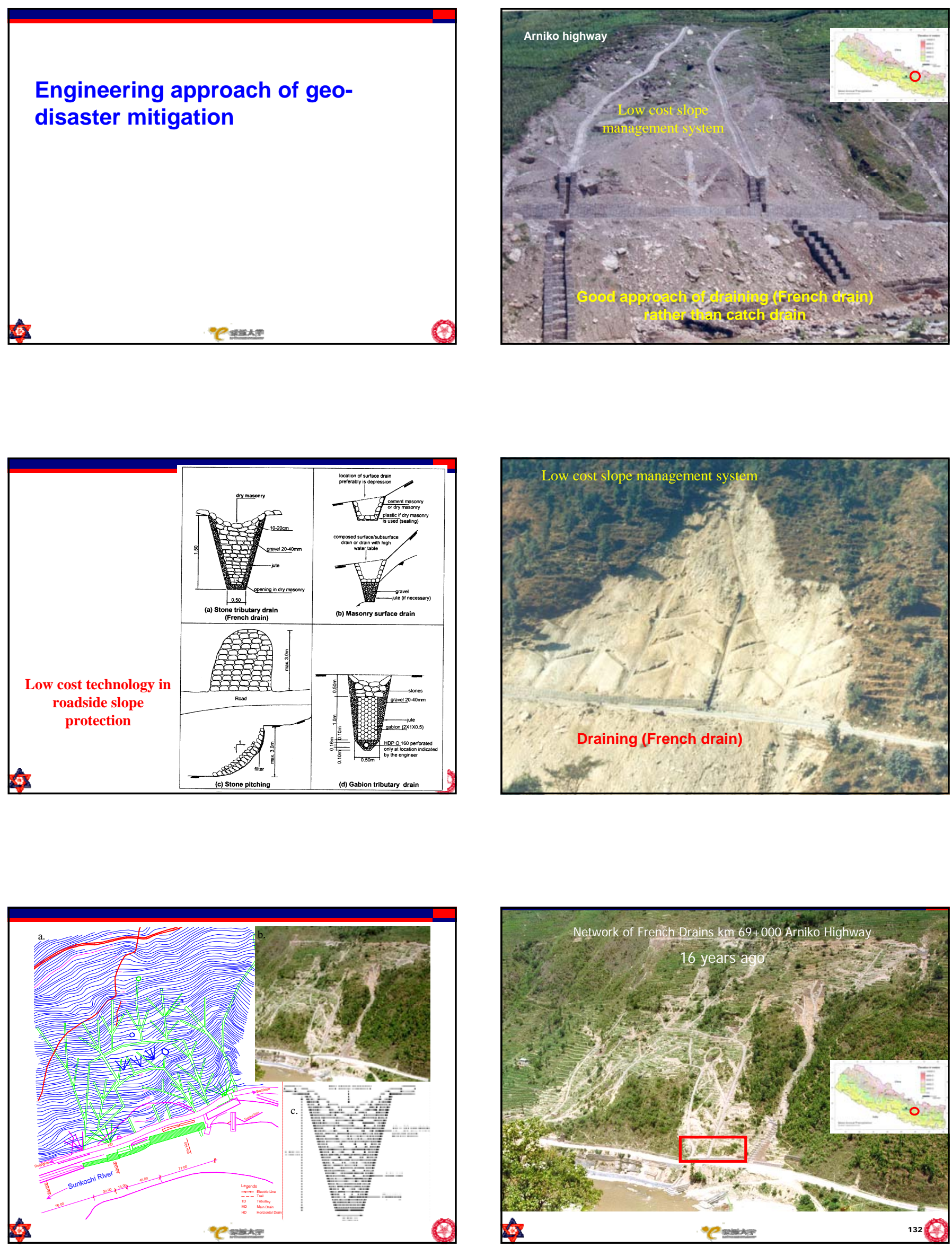

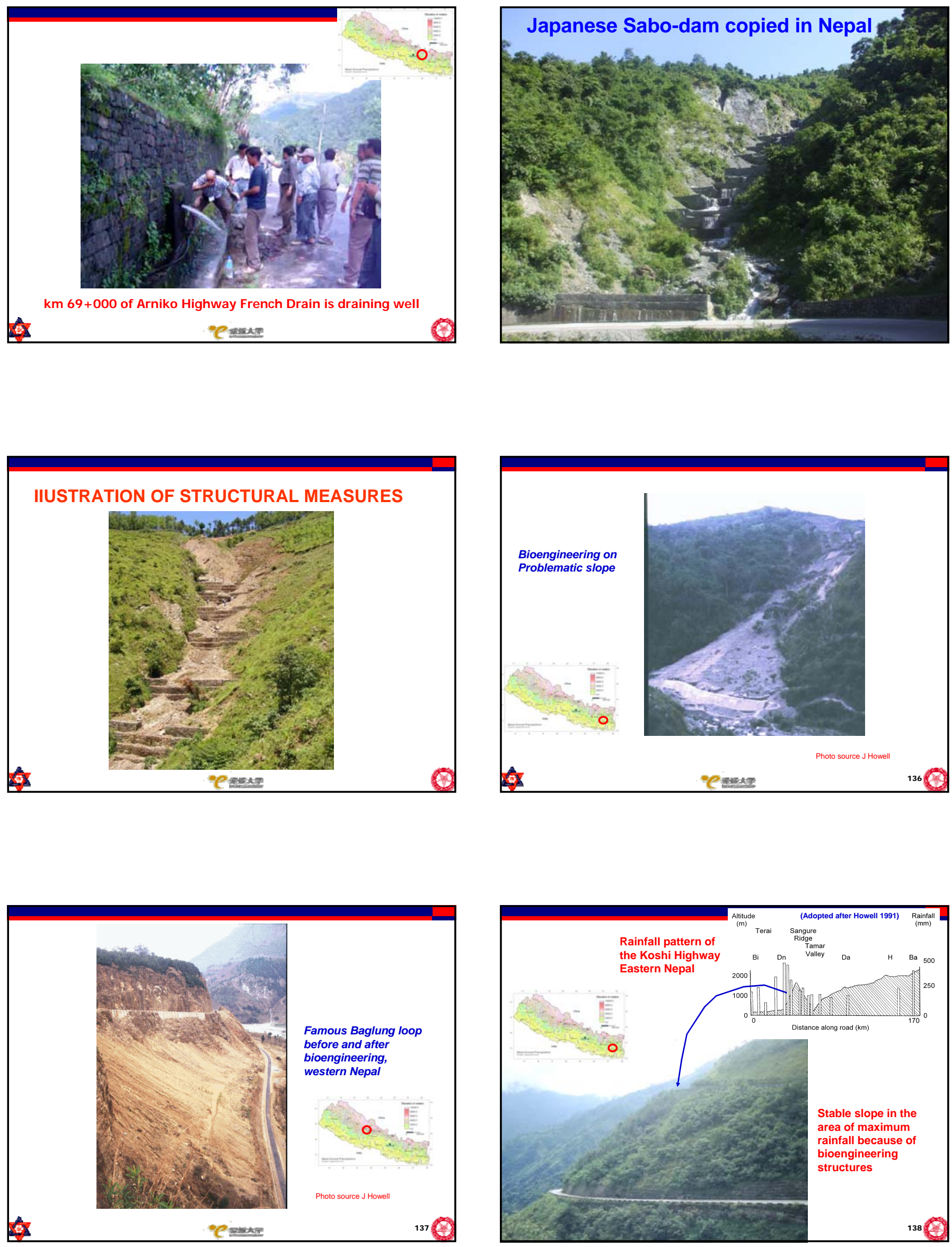

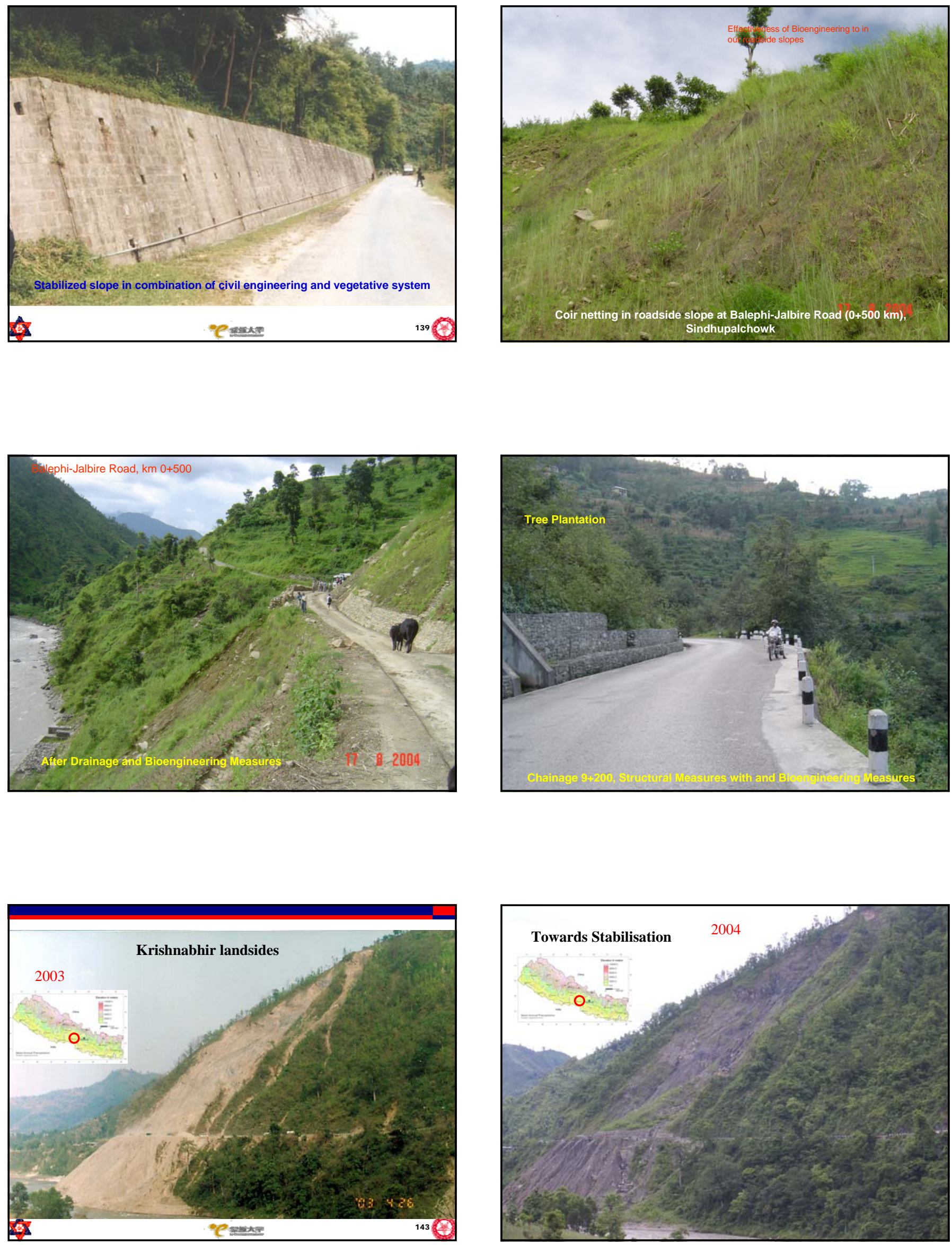

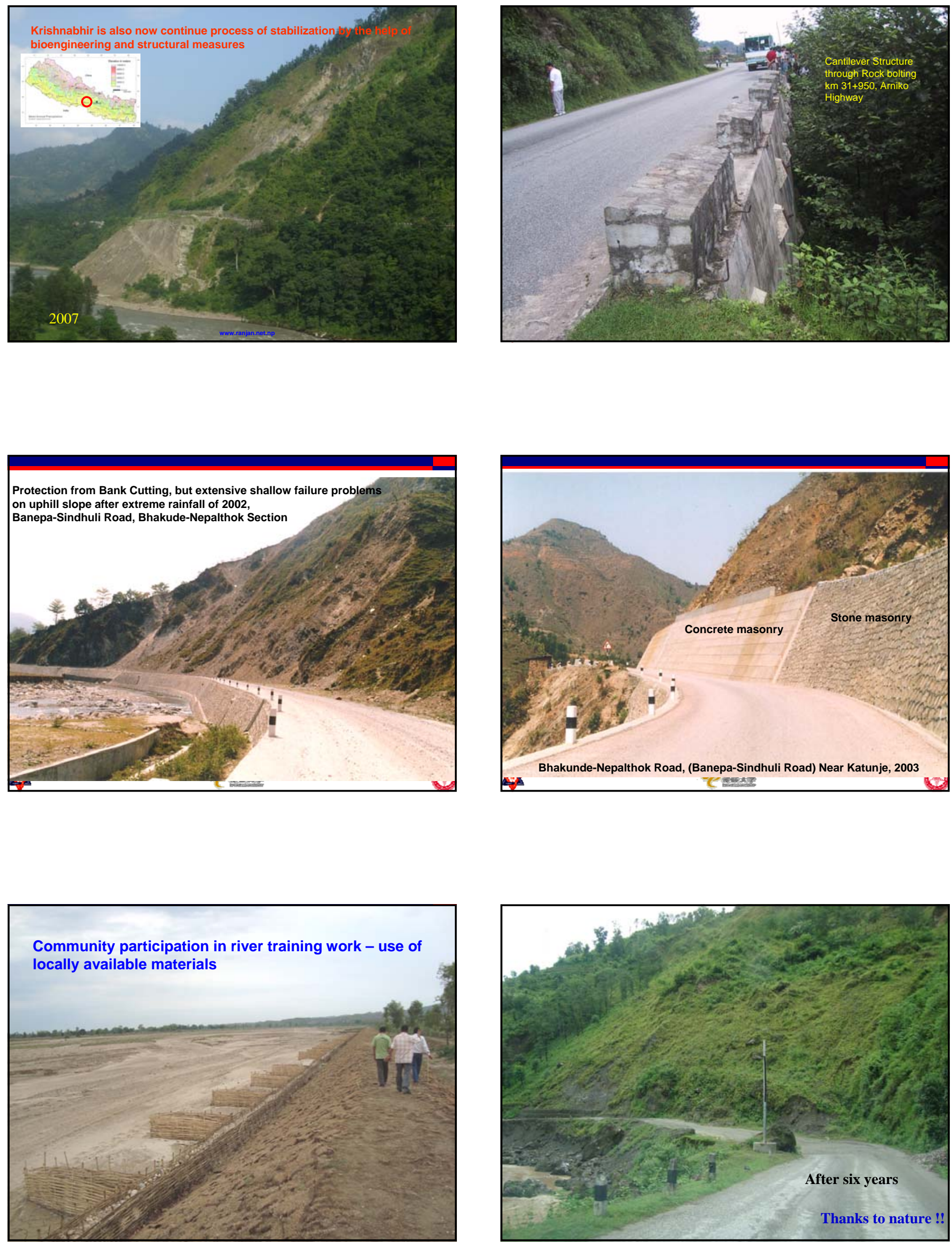
Rehabilitation Expenditure in Road due to Natural Disasters

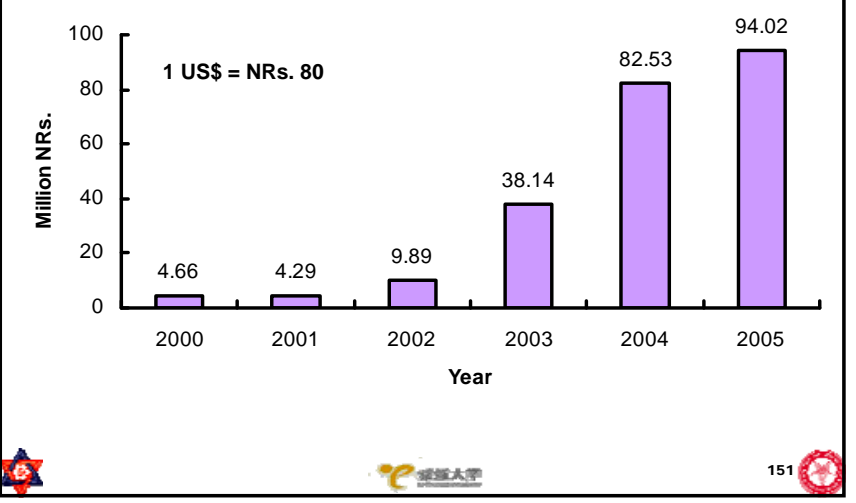

\section{Concluding remarks}

- Highly dynamic physical processes dominate the mountainous terrain of Nepal, and therefore, mitigating geo-disaster is a challenge.

- Monsoon rainfall is the main trigger of landslides and floods in Nepal

- Construction, maintenance and rehabilitation of infrastructure under the unique Himalayan condition require innovative and more pragmatic approach compared to less critical terrains in other parts of the world.

- Land management code should be implemented in coordination with landslide and flood hazard zonation map of the area

- "Low cost" infrastructure is not always right for low income countries like Nepal

A. elasuar

\section{Concluding remarks contd.}

- Over the years, Nepal has gained both good and bad experiences in geo-disaster mitigation:

$\square$ in design and survey of geo-disaster mitigation programs,

$\square$ in the fields of hazard and risk assessment,

$\square$ in low cost rural road engineering - how much bad and how much good

$\square$ in community based river training work, and

$\square$ in slope maintenance incorporating indigenous techniques.

- The governmental agencies involved in geo-disaster management must change their status from implementer to facilitator.

- Government should enhance institutional capacity building at local level to enable local bodies to undertake the immense responsibility of geo-disaster mitigation.

- Positive people perception for geo-disaster mitigation and community participations in mitigation program are very important for geo-disaster management in Nepal

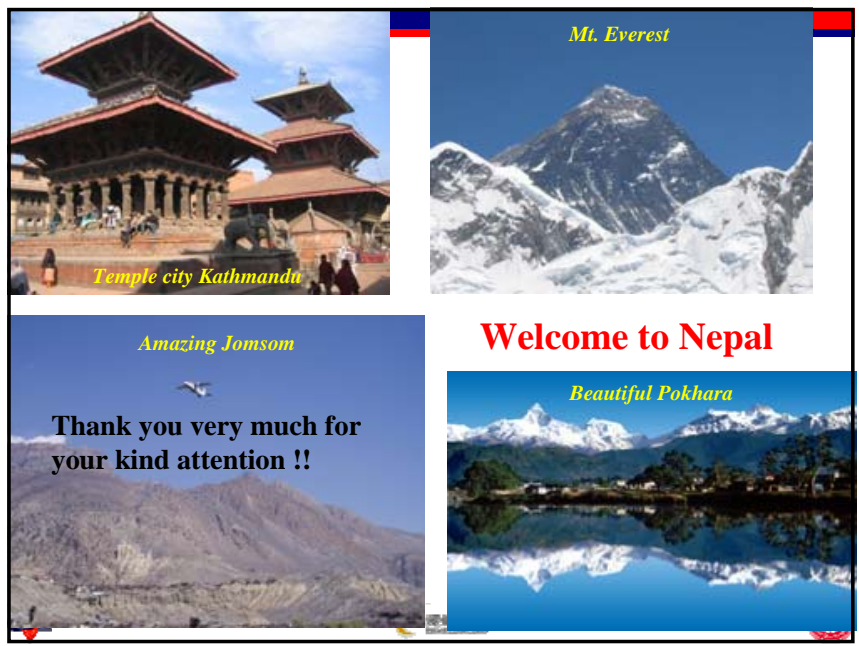

